\title{
Identification, Molecular Characterization and Pathological Features of Orf Virus in Sheep and Goats in Punjab Province, Pakistan
}

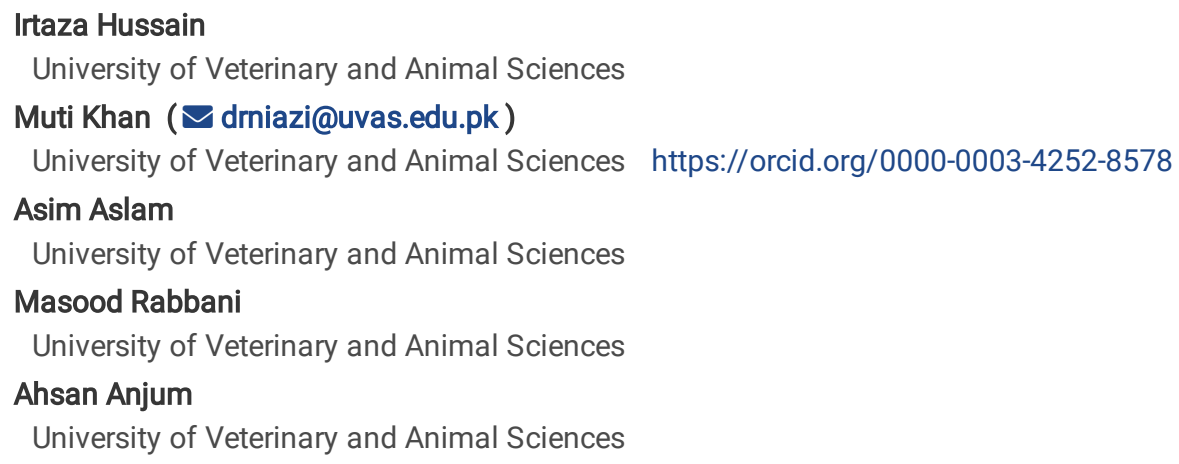

Research Article

Keywords: ORF virus, contagious ecthyma, histopathology, phylogenetic analysis, Pakistan

Posted Date: January 17th, 2022

DOI: https://doi.org/10.21203/rs.3.rs-1186022/v1

License: (c) (i) This work is licensed under a Creative Commons Attribution 4.0 International License. Read Full License 


\section{Abstract}

Orf virus (ORFV) causes an acute, contagious, skin disease of sheep and goats which is economically important. The objectives of this study were to identify ORFV and to explore its pathological and phylogenetic profiles in 350 goats and 91 sheep of 14 districts of Punjab, Pakistan, from July 2020 to July 2021. Skin scrapings (total no of samples=441) of suspected animals were subjected to polymerase chain reactions, phylogenetic analysis and pathological observations. The partial length of GIF/IL-2 gene (408 bp) was successfully amplified in 58/441 samples. Phylogenetic analysis of GIF/IL2 gene showed that the study isolates belonged to ORFV-cluster I, together with the viruses reported in India and China. Pakistan ORFV isolates were shared 97.6-98.7\% nucleotide and 97.6-100\% amino acid identities with the reference strain (NC_005336). Moreover, Chinese ORFV-isolates were detected unique multiple amino acid substitutions (F11L, Q21H, D27N, 146V, N49S, N82D, D103N, S129G) with study isolates. Naturally infected animals were anorexic, emaciated, dull, and depressed. The macroscopic lesions included multifocal to coalescing, ulceration followed by proliferative papules, pustules, and crust formation on the epidermis of gums, lips, mouth commissure, muzzles, nose and udder. Histopathological examination revealed hyperplasia, anastomosing rete ridges formation and degenerative changes, including spongiosis and vacuolation of epidermal cells. Keratinocytes exhibited eosinophilic intracytoplasmic inclusion bodies with pyknotic and karyorrhexis nuclei. This is the first report on molecular characterization of ORFV from Pakistan, with insight into its pathogenesis and comparative analysis of pathological alterations and genetic diversity between ORFV strains reported in different geographical areas.

\section{Introduction}

Orf virus (ORFV) is the prototype of the genus parapoxvirus, which causes contagious ecthyma, a non-systemic, highly contagious, debilitating and eruptive viral skin disease with worldwide distribution. The other members of parapoxvirus include bovine papular stomatitis virus (BPSV), pseudo-cowpox virus (PCPV), squirrel parapoxvirus and red deer parapoxvirus in New Zealand. ORFV induces ulcerative and proliferative skin lesions on lips, gums, nostrils, muzzles, teat, and oral commissures of sheep, goats, and wild ruminants. Humans may also develop lesions as a result of close interaction with infected animals and contaminated fomites. Though orf is considered as a mild disease, but high mortality rates during an outbreak are supposed to be attributable to secondary infections or sores around the mouths and lips of young animals, resulting in emaciation.

The ORFV genome is a linear double-stranded DNA molecule ( 135 kb). The central part of the genome is composed of conserved genes, required for virus replication and morphogenesis. In contrast, variable genes are present at terminal ends and primarily responsible for virus virulence and pathogenesis (Delhon et al. 2004). For genetic variation and molecular epidemiological studies, B2L, DNA polymerase, GIF/IL-2 and VIR genes are generally studied (Ramesh et al. 2008; Bora et al. 2012; Oem et al. 2013; Kumar et al. 2014).

The ORFV subverts the host immune response by releasing the virulence proteins that block the anti-inflammatory effector molecules (Haig and Fleming, 1999). The most important virulence proteins are chemokine-binding protein (CKBP), orf virus homologue of interleukin-10 (orfIL-10), vascular endothelial growth factor (VEGF-E), an interferon resistance protein (OVIFNR) resembling the vaccinia virus E3L gene, and GIF a secreted dual inhibitor of both granulocyte-macrophage colony-stimulating factor (GM-CSF) and interleukin (IL-2) (Seet et al. 2003; Haig et al.

2002; Lyttle et al. 1994; Haig et al. 1998; Deane et al. 2000)

GIF is probably one of the most intriguing viral proteins since it targets two unique host proteins essential for a robust immune response. GM-CSF, for example, plays a crucial role in the survival and activation of macrophages, neutrophils, and eosinophils, as well as the maturation of dendritic cells and the differentiation of invariant natural killer T cells (Hamilton, 2008). At the same time, IL-2 is required to maintain regulatory T cells and proliferation of B cells, memory T cells, and natural killer cells (Gaffen and Liu, 2004; Boyman and Sprent, 2012).

In recent years, outbreaks of ORFV have been reported in Bangladesh (Azad et al. 2016), India (Venkatesan et al. 2018; Nagarajan et al. 2019; Karki et al. 2020), Iran (Oryan et al. 2017), and China (Yu et al. 2017; Zhong et al. 2019). However, there is a paucity of literature addressing the emergence and pathological features of ORFV in Pakistan. Therefore, this study was aimed; (1) to investigate the presence of ORFVs in highly rich small ruminant districts of Punjab province in Pakistan (2) molecular characterization of existing ORFV isolated from field cases in 14 districts of Punjab, (3) to explore the macro and micro-pathological manifestations associated with ORFV in naturally infected small ruminants.

\section{Materials And Methods}

\section{Ethical approval}

The present work was approved by the ethical review committee of the University of Veterinary and Animal Sciences (UVAS), Lahore, Pakistan (Permit Number: DR/452).

\section{Sample collection}

The study was conducted from July 2020 to July 2021 in highly populated and small animal rich 14 districts of Punjab, Pakistan (Fig. 1). Skin scrapings $(n=441)$ from oral commissure, lips, muzzles and nose of sheep $(n=91)$ and goat $(n=350)$ from the different herds were collected. The 
animals that suffering from nodular to diffuse proliferative skin lesions were considered for sample collection and further for virus isolation. The tissue sample ( $2 \mathrm{~g}$ approximately) from each of the selected animal were placed in a sterile labeled universal tube (sterile $7.0 \mathrm{~mL}$ polystyrene Bijou container) supplemented with viral transport medium containing antibiotics (penicillin 1,000 IU/mL, streptomycin 1,000 $\mu \mathrm{g} / \mathrm{mL}, \mathrm{kanamycin} 500$ $\mu \mathrm{g} / \mathrm{mL}$ ) and antifungal (amphotericin B $25 \mathrm{mg} / \mathrm{mL}$ ) reagents. The collected samples were stored at $-20^{\circ} \mathrm{C}$ until further laboratory analysis. For histopathological studies another part of scab tissue/affected skin along with healthy tissues were preserved in $10 \%$ neutral buffer formalin.

\section{Viral Genome extraction}

The viral genome was extracted according to the protocol described by Zhong et al. (2019). Briefly, after removal from viral transport medium through centrifugation, the skin scrapings/ tissue samples were separately triturated in sterile PBS containing antibiotics (penicillin 1,000 IU/mL, streptomycin $1,000 \mu \mathrm{g} / \mathrm{mL}$, kanamycin $500 \mu \mathrm{g} / \mathrm{mL}$ ) and antifungal (amphotericin B $25 \mathrm{mg} / \mathrm{mL}$ ), making a final (10\% w/v) solution. Each of the tissue homogenate was centrifuged at $8,000 \mathrm{~g}$ for $10 \mathrm{~min}$ at $4{ }^{\circ} \mathrm{C}$. The supernatants were subjected for genome extraction using the GeneJET Genomic DNA Purification Kit (Thermo Fisher Scientific, Catalog Number: K0722), following the manufacturer's guidelines. Briefly, $200 \mu \mathrm{L}$ supernatant was admixed with digestion solution $(180 \mu \mathrm{L})$ and Proteinase $\mathrm{K}(20 \mu \mathrm{L})$. The mixture was incubated overnight at $56^{\circ} \mathrm{C}$ for complete cell lysis. Finally, the genomic DNA was extracted following the subsequent addition of RNase A solution $(20 \mu \mathrm{L})$, lysis solution $(200 \mu \mathrm{L}), 50 \%$ ethanol $(400 \mu \mathrm{L})$, wash buffer-I $(500 \mu \mathrm{L})$, wash buffer-II $(500 \mu \mathrm{L})$, and elution buffer $(30 \mu \mathrm{L})$. The concentration of eluding DNA was measured using a spectrophotometer (Nanodrop, USA).

\section{ORFV gene detection through Polymerase chain reaction}

The isolated DNA fragment from processed samples were amplified through polymerase chain reaction (PCR) in a $40 \mu \mathrm{L}$ reaction mixture, containing $20 \mu \mathrm{L}$ master mix (PrimeSTAR Max DNA polymerase, Catalog Number: R045A), $2 \mu \mathrm{L}$ DNA template, $2 \mu \mathrm{L}$ each forward and reverse primers and $14 \mu \mathrm{L}$ PCR grade water. Previously reported GIF/IL-2 gene-based primers; F(5'-GCTCTAGGAAAGATGGCGTG-3') and R(5'-

GTACTCCTGGCTGAAGAGCG-3') with an estimated amplicon size of 408 bp were employed for this reaction (Maan et al. 2014). The reaction mixture was subjected to initial denaturation $\left(95^{\circ} \mathrm{C}\right.$ for $\left.5 \mathrm{~min}\right)$, with subsequent 35 cycles of denaturation $\left(94^{\circ} \mathrm{C}\right.$ for 30 sec), annealing $\left(58^{\circ} \mathrm{C}\right.$ for $30 \mathrm{sec}$ ) and extension $\left(72^{\circ} \mathrm{C}\right.$ for $\left.45 \mathrm{sec}\right)$ followed by a final extension at $72^{\circ} \mathrm{C}$ for $7 \mathrm{~min}$. An individual aliquot of PCR product ( $\left.5 \mu \mathrm{L}\right)$ was checked using $1.5 \%$ agarose gel, stained with GelRed ${ }^{\mathrm{TM}}$ Nucleic Acid Gel Stain in gel electrophoresis at $110 \mathrm{~V}, 230 \mathrm{~mA}$ for 45 min and visualized in a gel documentation system (Bio-Rad Laboratories, United States).

\section{ORFV gene Sequencing and phylogenetic analysis}

Amplified PCR product was purified using GeneJET PCR Purification Kit (Thermo Fischer Scientific, Catalog Number: K0702). The samples were submitted to Comate Bioscience Co., Ltd., China, for sequencing (Sanger method). The obtained nucleotide sequences were properly trimmed with Chromas Software (version 2.6.6). The resulting sequences were compared with the ORFV reference virus sequence (Accession No.: NC_005336) through NCBI BLAST. Multiple sequence alignments were performed on BioEdit Software (version 7.2.5) using the ClustalW. The phylogenetic tree was constructed on MEGA Software (version 6) and inferred through the Neighbor-Joining method with the maximum composite likelihood. The reliability of the tree was tested by performing 1,000 bootstrap replicates (Tamura et al. 2013). The pairwise nucleotide and amino acid distance matrix were calculated with Genious Software (version 7.0.6). The identity matrix among the study isolates was also generated with Sequence Demarcation Tool (SDT) Software (version 1.2) in muscle mode with an identity cut-off value set at 98\% (Muhire et al. 2014). The evolutionary network of parapoxviruses was constructed using the Neighbor-Net graph technique based on the pairwise distance measured using uncorrected p-distance and angle split transformation settings in Splits Tree Program (version 4.95).

\section{Clinical signs, symptoms, gross lesions and histopathological and microscopic studies of PCR based confirmed ORFV cases}

PCR based confirmed cases were further explored for included in clinical signs, symptoms, gross lesions and histopathological studies. The skin surfaces of oral commissure, lips, muzzles, and nose of affected animals were properly observed for pathological lesions. Also, the skin scrapings were fixed in $10 \%$ neutral buffered formalin (NBF) for microscopic evaluations. The tissue samples were sectioned, hydrated in running tap water, dehydrated in ascending order of ethanol (70\%, 85\%, 95\%, 100\% I and 100\% II), embedded in paraffin, and sliced (4 $\mu \mathrm{m})$ with a microtome (SLEE, Germany). The tissue samples were subjected to staining (hematoxylin and eosin dye) and analyzed under a light microscope (Olympus, Japan) (Anjum et al. 2020).

\section{Results}

\section{Accession numbers of study isolates}

The partial length GIF/IL-2 gene (408 bp) was successfully isolated in 58/441 animals (51 goats, 7 sheep) (Fig. 2). The detail of isolated samples from different districts is listed in Table 1. The nucleotide sequences of the current study were submitted to NCBI GenBank Database and are available under the following accession numbers; MZ054288 (orfV/Lodhran/1/Goat/2020/Pakistan), MZ054291 (orfV/Lodhran/5/Goat/2020/Pakistan), MZ054297(orfV/Muzaffargarh/18/Sheep/2020/Pakistan), MZ054293 (orfV/Dera Ghazi 
Khan/8/Goat/2020/Pakistan), MZ054285 (orfV/Multan/20/Goat/2020/Pakistan), MZ054292 (orfV/Dera Ghazi Khan/6/Goat/2020/Pakistan), MZ054299 (orfV/Lahore/22/Goat/2020/Pakistan), MZ054286 (orfV/Lahore/23/Goat/2020/Pakistan), MZ054281 (orfV/Dera Ghazi Khan/9/Goat/2020/Pakistan).

\section{GIF/IL-2 gene sequence analysis}

The percentage identity matrix of GIF/IL2 gene of study isolates and other parapoxvirus retrieved from NCBI GenBank were demonstrated using similarity (\%) and pairwise distance matrix and tabulated separately for nucleotide (nt) (Table 2) and amino acid (aa) (Table 3). The results revealed that the Pakistan isolates had $94.4 \%$ 99.9\% and 96.7\% 99.9\% similarities at nt and aa level, respectively. Moreover, nucleotide homology (\%) of the study isolates with the reference strain of ORFV (NC_005336) is represented in Fig. 3a, which shared maximum nucleotide (97.2 98.7\%) and amino acid (97.6 100\%) sequence homology. Similarly, ORFV originated from neighboring countries (India and China) exhibited the highest identities, $98.1 \% \sim 99.9 \%$ and $99.2 \% \sim 99.9 \%$ at nt and aa levels, respectively (Fig. 3b). The nucleotide and amino acid sequence analysis revealed a close relationship between the study and neighboring countries isolates.

\section{Amino acid substitutions}

The alignment of amino acid sequences of GIF/IL2 gene of the study isolates with NCBI GenBank reference strain, ORFV/OVSA00/Goat/USA/2003 (NC_005336), is shown in Fig. 4a. Six isolates (MZ054297, MZ054293, MZ054285, MZ054292, MZ054299, and MZ054286) have no unique amino acid substitutions; however, the isolates (MZ054288, MZ054291) have only one substitution (R5W), while isolate (MZ054281) has three unique amino acid substitutions (S16N, H18P, D103N) with the reference strain. Analysis based on ORFV-GIF/IL2 gene of neighboring countries (India, China) revealed that Indian ORFV-isolates (DQ922634, KY077477, KY077478) have no amino acid substitutions with the study isolates. In contrast, Chinese ORFV-isolates (MF489140, MF489145, MF172958, KF726847, KF666566, MF489142) have unique multiple amino acid substitutions (F11L, Q21H, D27N, 146V, N49S, N82D, D103N, S129G) with the study isolates (Fig. 4b).

\section{Phylogenomic and evolutionary tree}

The phylogenetic analysis based on GIF/IL2 gene of 51 PPVs sequences revealed that ORFV lineages were broadly grouped into five distinct clusters/clade with $>75 \%$ bootstrap support (Fig. 5). Cluster I comprises goat-originated Asian ORFV isolates, while clusters II, III, and V include Chinese, Indian, and Iraq-originated sheep ORFV isolates. Muskox and mountain goats (USA) derived ORFV isolates were placed in a monophyletic clade (cluster IV). The isolates from Pakistan clustered together with the Chinese (AH1404, Xinjiang1, AH1612, AH-GY13, Shihezi3, Xinjiang2, AH1508, GZ18) and Indian isolates (MUK59/05, MLMR/TN, MEC/TN) into the same clade (cluster I). Also, an evolutionary tree based on GIF/IL2 gene sequences segregated the PPVs into three distinct groups; ORFV, PCPV and BPSV, representing a close relation between ORFV and PCPV in evolution, compared to BPSV (Fig. 6).

\section{Pre-requisites for Case Definition for ORFV in Pakistan}

\section{Clinical signs and symptoms}

Diseased animals exhibited different clinical manifestations such as anorexia, starvation, emaciation, decreased weight gain, depression, and dullness. The lambs and kids were severely affected due to restricted suckling and grazing. Female animals also have developed teat crusts, which may be associated with oral cavity lesions of suckling. Furthermore, some animals developed respiratory problems, which could be due to secondary bacterial infection or aspiration pneumonia caused by bottle-feeding. Moreover, ORFV promoted death in young animals and myiasis in adults, primarily observed in a warm climate.

\section{Gross lesions}

The infected animals had the typical multifocal to coalescing, ulcerated lesions on the epidermis of gums, lips, mouth commeasure, muzzles, nose, and udder (Fig. 7a, 7b, 7c). Also, infected animals had severe proliferative papules, pustules, and crust formation (Fig. 7d, 7e). However, some animals also had the advanced stage in thicker, brownish, quickly accretive scabs with granulation (Fig. 7f, 7g, 7h). In addition, some animals exhibited the healing and regeneration stage of lesions (Fig. 7i).

\section{Histopathological and Microscopic analysis}

Histopathological examinations revealed epidermal hyperplasia with hyperkeratosis and parakeratosis with prominent thickening of epidermis resulted in acanthosis (Fig. 8a). Epidermal degeneration is characterized by lysis of epithelium replaced by a multifocal-to-coalescing necrotizing sero-cellular crust (Fig. 8b). The epidermis extends into the dermis and forms anastomosing rete ridges (Fig. 8c). Spinous cells in the stratum spinosum showed degenerative changes, including spongiosis and vacuolation with pyknotic and karyorrhexis nuclei (Fig. 8d). The epidermis contained peripheralized keratohyalin granules (Fig. 8h), micro abscess, and scab formation (Fig. 8e). Typical intraepithelial ballooning degeneration and eosinophilic intracytoplasmic inclusion bodies were detected in keratinocytes (Fig. 8g). The superficial dermis is expanded by infiltration of inflammatory cells (Fig 8f), intracellular edema and scattered hemorrhages (Fig. 8i). 


\section{Discussion}

Cases are reported from Pakistan (believed to be endemic) but prevalence reports are very few (Abbas and Mughal, 2014). The percentage positivity of ORFVs from 14 districts of Punjab, Pakistan confirmed through PCR showing percentage of $15 \%$ in goats and $8 \%$ in sheep. This is the first study which reports phylogeny of GIF/LL-2 gene of contagious ecthyma present in small ruminants (sheep and goat) in Punjab, Pakistan. Pathological findings are helpful in proper understanding of the disease pattern.

The percentage identity matrix of GIF/IL2 gene of study isolates not only show the great identities with other parapoxvirus retrieved from NCBI GenBank but also have the greatest identities with India and China isolates with more than 98 percent and 99 percent, respectively, at the nucleotide and amino acid levels. The nucleotide and amino acid sequence analysis revealed a strong link between the isolates from the research and those from adjacent countries. The amino acid sequences of the GIF/IL2 gene of the study revealing that one isolate have only one substitution and the other isolate has three. In comparison, Indian ORFV isolates show no amino acid substitutions with the study isolates, while Chinese ORFV isolates, on the other hand, show several amino acid changes that are distinct. Unique substitution in amino acids is evident in part of gene GIF/IL2; whole genome has to study in order to depict major substitutions in amino acids. ORFV lineages are broadly classified into five separate clusters/clades with $>75$ percent bootstrap support, according to phylogenetic analysis based on GIF/IL2 gene of 51 PPVs sequences, which was compatible with Zhao et al. (2010), Li et al. (2013), and Kumar et al (2014). Cluster I contains Asian ORFV strains derived from goats, with Pakistani isolates clustered alongside Chinese and Indian isolates. In addition, an evolutionary tree based on GIF/IL2 gene sequences divided the PPVs into three groups: ORFV, PCPV, and BPSV, indicating an adjacent evolutionary relationship between ORFV and PCPV compared to BPSV. Our findings are consistent with those of earlier investigations (Chan et al. 2007; Oem et al. 2009; Zhao et al. 2010; Friederichs et al. 2014; Khalafalla et al. 2020).

Adult animals with the disease developed anorexia, which resulted in the reduction of weight gain. The lambs and kids are seriously affected due to lacking of feeding and those who were able to suckle the milk from the dam developed oral cavity lesions from the affected teats with contagious ecthyma. Furthermore, aspiration pneumonia is caused by bottle-feeding. The clinical symptoms observed in this investigation are consistent with previous research findings (Housawi, 2002; Guo et al. 2003; Guo et al. 2004; Chan et al. 2007). On the epidermis of the gums, lips, mouth commeasure, muzzles, nose, and udder, the infected animals had the characteristic multifocal to coalescing, ulcerated lesions. Infected animals also developed significant proliferative papules, pustules, crusting, and brownish scabs. Previous studies (Zhao et al. 2010; Nandi et al. 2011; Kinley et al. 2013; Al-Saad et al. 2017; zmen and Dolu, 2018; Aneed and Al-Saad, 2019; Milovanovi et al. 2019) had found that the macroscopic lesions seen in this study were inconsistent with ORFV infection in sheep and goats. Orf pustules occur within a few days, followed by ulcers and a thick scab formation (3-4 weeks), with no scar tissue formation (De La Concha-Bermejillo et al. 2003; Abbas and Mughal, 2014). The etiological agent may cause superficial lesions to become crusted, scab over, and fall off. Furthermore, opportunistic microorganisms may infiltrate these wounds, causing illness to spread (Kumar et al. 2015). Marked epidermal hyperplasia, ballooning degeneration, and eosinophilic intracytoplasmic inclusion bodies within keratinocytes are characteristics microscopic lesions of the vesicular stage (Sanchez et al. 1985; Barraviera 2005; Chan et al. 2007; Turan et al. 2013; Tahir et al. 2014; Vellucci et al. 2020). Also, keratohyalin granules are primarily found in the stratum granulosum and spinosum. These granules are water-insoluble and exist in the cytoplasm to promote cell dehydration. During keratinocyte differentiation, these granules undergo cellular adaptations resulting in the transformation of keratin tonofilaments into a homogeneous keratin matrix, an important phase in cornification (Hermanns-Lê et al. 2004); Takahashi et al. 2010). Furthermore, bacterial infections are frequently evident in the affected skin; however, paramyxovirus is attached to intracytoplasmic inclusion bodies in the form of typical brick-shaped virions (Nandi et al. 2011; Karki et al. 2019).

\section{Conclusion}

The current study is the first phylogenetic analysis-based investigation of ORFV isolated from Pakistan, and it reveals two distinct clusters within the same phylogenetic group. Pakistan-originated ORFV are genetically heterogeneous but closely related to ORFV strains reported in neighboring countries (India and China). Also, this is the first report on pathological manifestations observed in small ruminants in Pakistan. Considering ORF as an unreported disease, we expect that many cases remain unidentified, which suggest the actual diversity is likely even higher in Pakistan. Therefore, a holistic approach is required to identify the genetic diversity and biological features of Pakistan-originated ORFV strains.

\section{Declarations}

Funding: This study was funded by the Higher Education Commission of Pakistan under the project "Faculty Development Program for Pakistani Universities" Batch II (17-5/FVS2-001/HEC/Sch-FDP/2019).

Conflicts of interest/Competing interests: The authors declare that they have no conflict of interest.

Ethics approval: All the procedures performed in this study were in accordance with the ethical standards of the University of Veterinary and Animal Sciences, Lahore, Pakistan, and approval was granted by the Animal Ethical Review Committee. 
Consent to publication: Not applicable

Availability of data and material: The authors declare that all the data and materials used in this study comply with field standards and available on demand.

Code availability: Not applicable

Authors' contributions: Irtaza Hussain conducted this study as part of his PhD research work under the supervision of Muti ur Rehman Khan, Asim Aslam, and Masood Rabbani. Ahsan Anjum helped in data collection and helped in the lab work, statistical analysis and formatting of the manuscript. Muti ur Rehman Khan, Asim Aslam, and Masood Rabbani helped in reviewing the manuscript. All authors read and approve the final manuscript.

\section{References}

1. Abbas, G. and Mughal, M., 2014. Case report on orf in sheep in Faisalabad Pakistan. International Journal of Molecular Veterinary Research 4, $1-2$.

2. Aneed, A. and Al-Saad, K., 2019. Study of contagious ecthyma in lambs of Basrah province, Iraq. Basrah Journal of Veterinary Research 18, 27-55.

3. Anjum, A., Aslam, A., Akhtar, R., Yaqub, T., Khan, M.R., Sultan, R., Usman, S., Durrani, A.Z. and Usman, M., 2020. Molecular detection and pathological investigation of contagious bovine pleuropneumonia in selected districts of Punjab, Pakistan. Pakistan Journal of Zoology 52 , 797-800.

4. Azad, M.T.A., Saha, S., Alam, M.S., Monoura, P., Giasuddin, M., Islam, S.M.S., Taimur, M.J.F.A. and Alam, J., 2016. Epidemiological investigation and phylogenetic analyses of contagious ecthyma virus from goat in Bangladesh. Asian Journal of Medical and Biological Research 2, 555-561.

5. Barraviera, S.R.C.S., 2005. Diseases caused by poxvirus - orf and milker's nodules: a review. Journal of Venomous Animals and Toxins including Tropical Diseases 11, 102-108.

6. Bora, D.P., Barman, N.N., Das, S.K., Bhanuprakash, V., Yogisharadhya, R., Venkatesan, G., Kumar, A., Rajbongshi, G., Khatoon, E., Chakraborty, A. and Bujarbaruah, K.M., 2012. Identification and phylogenetic analysis of orf viruses isolated from outbreaks in goats of Assam, a northeastern state of India. Virus Genes 45, 98-104.

7. Boyman, O. and Sprent, J., 2012. The role of interleukin-2 during homeostasis and activation of the immune system. Nature Reviews Immunology 12, 180-190.

8. Chan, K.W., Lin, J.W., Lee, S.H., Liao, C.J., Tsai, M.C., Hsu, W.L., Wong, M.L. and Shih, H.C., 2007. Identification and phylogenetic analysis of orf virus from goats in Taiwan. Virus genes 35, 705-712.

9. De La Concha-Bermejillo, A., Guo, J., Zhang, Z. and Waldron, D., 2003. Severe persistent orf in young goats. Journal of Veterinary Diagnostic and Investigation 15, 423-431.

10. Deane, D., Mcinees, C.J., Percival, A., Wood, A., Thomson, J., Lear, A., Gilray, J., Fleming, S., Mercer, A. and Haig, D., 2000. Orf virus encodes a novel secreted protein inhibitor of granulocyte-macrophage colony-stimulating factor and interleukin-2. Journal of Virology $74,1320$.

11. Delhon, G., Tulman, E.R., Afonso, C.L., Lu, Z., de La Concha-bermejillo, A., Lehmkuhl, H.D., Piccone, M.E., Kutish, G.F. and Rock, D.L., 2004. Genomes of the parapoxviruses ORF virus and bovine papular stomatitis virus. Journal of Virology 78, 168-177.

12. Friederichs, S., Krebs, S., Blum, H., Wolf, E., Lang, H., Von Buttlar, H. and Buttner, M., 2014. Comparative and retrospective molecular analysis of Parapoxvirus (PPV) isolates. Virus Research 181, 11-21.

13. Gaffen, S.L. and Liu, K.D., 2004. Overview of interleukin-2 function, production and clinical applications. Cytokine 28, 109-123.

14. Guo, J., Rasmussen, J., Wunschmann, A. and De La Concha-Bermejillo, A., 2004. Genetic characterization of orf viruses isolated from various ruminant species of a zoo. Veterinary Microbiology 99, 81-92.

15. Guo, J., Zhang, Z., Edwards, J.F., Ermel, R.W., Taylor, C. and De La Concha-bermejillo, A., 2003. Characterization of a North American orf virus isolated from a goat with persistent, proliferative dermatitis. Virus Research 93, 169-179.

16. Haig, D.M. and Fleming, S., 1999. Immunomodulation by virulence proteins of the parapoxvirus orf virus. Veterinary Immunology and Immunopathology 72, 81-86.

17. Haig, D.M., Mcinnes, C.J., Thomson, J., Wood, A., Bunyan, K. and Mercer, A., 1998. The orf virus OV20.0L gene product is involved in interferon resistance and inhibits an interferon-inducible, double-stranded RNA-dependent kinase. Immunology 93, 35-340.

18. Haig, D.M, Thomson, J., Mcinnes, C.J., Deane, D.L., Anderson, I.E., Mccaughan, C.A., Imlach, W., Mercer, A.A., Howard, C.J. and Fleming, S.B., 2002. A comparison of the anti-inflammatory and immuno-stimulatory activities of orf virus and ovine interleukin-10. Virus Research $90,303-$ 
316.

19. Hamilton, J.A., 2008. Colony-stimulating factors in inflammation and autoimmunity. Nature Reviews Immunology 8, 533-544.

20. Hermanns-Le, T., Garcia, R., Arrese, J.E. and Pierard, G.E., 2004. Pitted keratolysis: New ultrastructural insight in keratohyalin granule and corneodesmosome alterations. Exogenous Dermatology 3, 107-111.

21. Housawai, F.M.T., 2002. Biochemical changes associated with experimental orf infection in sheep and goats. Pakistan Veterinary Journal 22, 8-10.

22. Karki, M., Kumar, A., Arya, S. and Venkatesan, G., 2020. Circulation of orf viruses containing the NZ7-like vascular endothelial growth factor (VEGF-E) gene type in India. Virus Research 281, e197908.

23. Karki, M., Venkatesan, G., Kumar, A., Kumar, S. and Bora, D.P., 2019. Contagious ecthyma of sheep and goats: A comprehensive review on epidemiology, immunity, diagnostics and control measures. Veterinarski Archive 89, 393-423.

24. Khalafalla, A.I., Elhag, A.E. and Ishag, H.Z.A., 2020. Field investigation and phylogenetic characterization of orf virus (ORFV) circulating in small ruminants and Pseudocowpoxvirus (PCPV) in dromedary camels of eastern Sudan. Heliyon 6, e03595.

25. Kinley, G.E., Schmitt, C.W. and Stephens-Devalle, J., 2013. A case of contagious ecthyma (Orf Virus) in a nonmanipulated laboratory dorset sheep (Ovis aries). Case Reports in Veterinary Medicine 2013, 1-5.

26. Kumar, N., Wadhwa, A., Chaubey, K.K., Singh, S.V., Gupta, S., Sharma, S., Sharma, D.K., Singh, M.K. and Mishra, A.K., 2014. Isolation and phylogenetic analysis of an orf virus from sheep in Makhdoom, India. Virus Genes 48, 312-319.

27. Kumar, R., Trivedi, R.N., Bhatt, P., Khan, S.H., Khurana, S.K., Tiwari, R., Karthik, K., Malik, Y.S., Dhama, K. and Chandra, R., 2015. Contagious pustular dermatitis (orf disease)-epidemiology, diagnosis, control and public health concerns. Advances in Animal and Veterinary Sciences 3 , 560-569.

28. Li, H., Zhu, X., Zheng, Y., Wang, S., Liu, Z., Dou, Y., Li, H., Cai, X. and Luo, X., 2013. Phylogenetic analysis of two Chinese orf virus isolates based on sequences of B2L and VIR genes. Archives of Virology 158, 1477-1485.

29. Lyttle, D.J., Fraser, K.M., Fleming, S.B., Mercer, A.A. and Robinson, A.J., 1994. Homologs of vascular endothelial growth factor are encoded by the poxvirus orf virus. Journal of Virology 68, 84-92.

30. Maan, S., Kumar, A., Batra, K., Singh, M., Nanda, T., Ghosh, A. and Maan, N.S., 2014. Isolation and molecular characterization of contagious pustular dermatitis virus from Rajasthan, India. Virus Diseases 25, 376-380.

31. Milovanovic, M., Milicevic, V., Valcic, M., Stevic, N., Nisavic, J. and Radojicic, S., 2019. Detection and phylogenetic analysis of B2L gene of ORF virus from clinical cases of sheep in Serbia. Pakistan Veterinary Journal 39, 433-437.

32. Muhire, B.M., Varsani, A. and Martin, D.P., 2014. SDT: A Virus Classification Tool Based on Pairwise Sequence Alignment and Identity Calculation. PLOS ONE 9, e108277.

33. Nagarajan, G., Pourouchottamane, R., Reddy, G.B.M., Yogisharadhya, R., Sumana, K., Rajapandi, S., Murali, G., Thirumaran, S.M.K., Mallick, P.K. and Rajendiran, A.S., 2019. Molecular characterization of Orf virus isolates from Kodai hills, Tamil Nadu, India. Veterinary World $12,1027$.

34. Nandi, S., De, U.K. and Chowdhury, S., 2011. Current status of contagious ecthyma or orf disease in goat and sheep-A global perspective. Small Ruminant Research 96, 73-82.

35. Oem, J.K., Chung, J.Y., Kim, Y.J., Lee, K.K., Kim, S.H., Jung, B.Y. and Hyun, B.H., 2013. Isolation and characterization of orf viruses from Korean black goats. Journal of Veterinary Science 14, 230.

36. Oem, J.K., Roh, I.S., Lee, K.H., Lee, K.K., Kim, H.R., Jean, Y.H. and Lee, O.S., 2009. Phylogenetic analysis and characterization of Korean orf virus from dairy goats: case report. Virology Journal 6, 1-5.

37. Oryan, A., Mosadeghhesari, M., Zibaee, S. and Mohammadi, A., 2017. Identification and phylogenetic analysis of contagious ecthyma virus from camels (Camelus dromedarius) in Iran. Onderstepoort Journal of Veterinary Research 84, 1-5.

38. Ozmen, O. and Dolu, H., 2018. Pathological and electron microscopical observations on naturally occurring contagious ecthyma outbreak in two wild goats (Capra aegagrus aegragus). Ankara Üniv Vet Fak Derg. 65, 419-423.

39. Ramesh, A., Vadivoo, V., Suresh-Babu, S. and Saravanabava, K., 2008. Confirmatory diagnosis of contagious ecthyma by amplification of the GIF/IL-2 gene by PCR. Tamilnadu Journal of Veterinary and Animal Sciences 4, 208-210.

40. Al-Saad, K., Thweni, H., Abdali, D. and Tarik, A., 2017. Clinical and diagnostic studies of contagious ecthyma (ORF) in sheep. IOSR Journal of Agriculture and Veterinary Science 10, 64-69.

41. Sanchez, R.L., Hebert, A., Lucia, H. and Swedo, J. 1985. Orf. A case report with histologic, electron microscopic, and immunoperoxidase studies. Archives of pathology \& laboratory medicine 109, 166-170.

42. Seet, B.T., Mccaughan, C.A., Handel, T.M., Mercher, A., Brunetti, C., Mcfadden, G. and Fleming, S.B., 2003. Analysis of an orf virus chemokinebinding protein: Shifting ligand specificities among a family of poxvirus viroceptors. Proceedings of the National Academy of Sciences of the United States of America 100, 15142. 
43. Tahir, M., Dar, N., Mumtaz, J., Anwar, I. and Mustafvi, S., 2014. Orf with unusual features. Journal of the College of Physicians and SurgeonsPakistan 24, 174-175.

44. Takahashi, M., Horiuchi, Y. and Tezuka, T., 2010. Hematoxylin-stainability of keratohyalin granules is due to the novel component, fibrinogen $Y$-chain protein. Archives of Dermatological Research 302, 679-684.

45. Tamura, K., Stecher, G., Peterson, D., Filipski, A. and Kumar, S., 2013. MEGA6: Molecular Evolutionary Genetics Analysis Version 6.0. Molecular Biology and Evolution 30, 2725-2729.

46. Turan, E., Yesilova, Y. and Ucmak, D., 2013. A case of orf (ecthyma contagiosum) with multiple lesions. Journal of the Pakistan Medical Association 63, 786-787.

47. Vellucci, A., Manolas, M., Jin, S., Dwyer, J., Vick, G., Wang, A., Swiatlo, E. and Zheng, C., 2020. Orf virus infection after Eid al-Adha. IDCases 21, e00854.

48. Venkatesan, G., De, A., Arya, S., Kumar, A., Muthuchelvan, D., Debnath, B.C., Dutta, T.K., Hemadri, D. and Pandey, A.B., 2018. Molecular evidence and phylogenetic analysis of orf virus isolates from outbreaks in Tripura state of North-East India. Virus Disease 29, $216-220$.

49. Yu, Y., Tan, Q., Zhao, W., Zhang, X., Ma, J., Wu, Z., Zhu, Z. and Cui, Y. 2017. Characterization of an orf virus isolate from an outbreak in Heilongjiang province, China. Archives of Virology 162, 3143-3149.

50. Zhao, K., Song, D., He, W., Lu, H., Zhang, B., Li, C., Chen, K. and Gao, F., 2010. Identification and phylogenetic analysis of an Orf virus isolated from an outbreak in sheep in the Jilin province of China. Veterinary Microbiology 142, 408-415.

51. Zhong, J., Guan, J., Zhou, Y., Cui, S., Wang, Z., Zhou, S., Xu, M., Wei, X., Gao, Y., Zhai, S., Song, D., He, W., Gao, F. and Zhao, K., 2019. Genomic characterization of two Orf virus isolates from Jilin province in China. Virus Genes55, 490-501.

\section{Tables}

Table 1. The percentage positivity of ORFV among tissue samples collected from different districts of Punjab, Pakistan confirmed through PCR

\begin{tabular}{|c|c|c|c|c|c|}
\hline \multirow[t]{2}{*}{ Districts } & \multicolumn{2}{|l|}{ Goat } & \multicolumn{2}{|l|}{ Sheep } & \multirow[b]{2}{*}{ Table 2. Nucleotide } \\
\hline & Positive samples/total samples & Positivity (\%) & Positive samples/total samples & Positivity (\%) & \\
\hline Bahawalnagar & $0 / 32$ & 0.00 & $0 / 5$ & 0.00 & identity matrix of field \\
\hline Bahawalpur & $0 / 39$ & 0.00 & $0 / 5$ & 0.00 & $\begin{array}{l}\text { ORFV Isolates with } \\
\text { other parapoxviruses }\end{array}$ \\
\hline Bhakkar & $0 / 26$ & 0.00 & $0 / 0$ & 0.00 & reported in different \\
\hline Dera Ghazi Khan & $12 / 29$ & 41.38 & $0 / 9$ & 0.00 & geographical areas \\
\hline Jhang & $0 / 18$ & 0.00 & $0 / 6$ & 0.00 & BPSV: Bovine papular \\
\hline Kasur & $0 / 17$ & 0.00 & $0 / 2$ & 0.00 & $\begin{array}{l}\text { stomatitis virus; } \\
\text { PCPV: Pseudocowpox }\end{array}$ \\
\hline Khushab & $0 / 22$ & 0.00 & $0 / 7$ & 0.00 & virus \\
\hline Lahore & $17 / 35$ & 48.57 & $0 / 4$ & 0.00 & Table 3. Amino acid \\
\hline Layyah & $0 / 15$ & 0.00 & $0 / 3$ & 0.00 & identity matrix of field \\
\hline Lodhran & $14 / 33$ & 42.42 & $0 / 8$ & 0.00 & ORFV isolates with \\
\hline Multan & $8 / 28$ & 28.57 & $0 / 8$ & 0.00 & reported in different \\
\hline Muzaffargarh & $0 / 25$ & 0.00 & $7 / 13$ & 53.85 & geographical areas \\
\hline Rahim Yar Khan & $0 / 13$ & 0.00 & $0 / 14$ & 0.00 & BPSV: Bovine papular \\
\hline Rajan Pur & $0 / 18$ & 0.00 & $0 / 7$ & 0.00 & $\begin{array}{l}\text { stomatitis virus; } \\
\text { PCPV: Pseudocowpox }\end{array}$ \\
\hline
\end{tabular}

virus

\section{Figures}

\section{Figure 1}




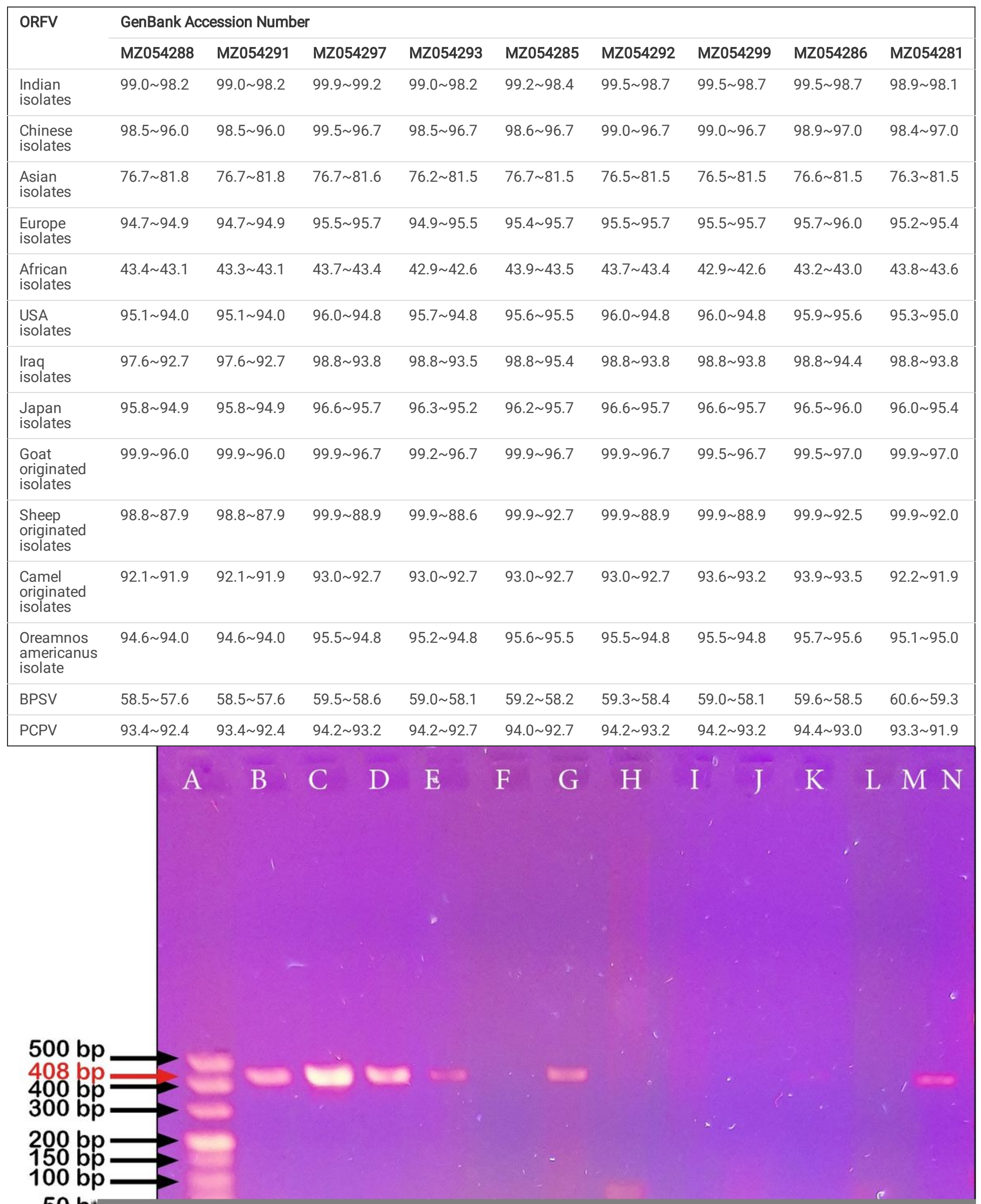




\begin{tabular}{|c|c|c|c|c|c|c|c|c|c|}
\hline \multirow[t]{2}{*}{ ORFV } & \multicolumn{9}{|c|}{ GenBank Accession Number } \\
\hline & MZ054288 & MZ054291 & MZ054297 & MZ054293 & MZ054285 & MZ054292 & MZ054299 & MZ054286 & MZ054281 \\
\hline $\begin{array}{l}\text { Indian } \\
\text { isolates }\end{array}$ & $99.4 \sim 99.2$ & $99.4 \sim 99.2$ & $99.9 \sim 99.7$ & $99.9 \sim 99.7$ & $99.9 \sim 99.7$ & $99.9 \sim 99.7$ & $99.9 \sim 99.7$ & $99.9 \sim 99.7$ & $97.9 \sim 97.6$ \\
\hline $\begin{array}{l}\text { Chinese } \\
\text { isolates }\end{array}$ & $94.7 \sim 99.2$ & $94.7 \sim 99.2$ & $99.9 \sim 95.5$ & $99.9 \sim 95.5$ & $99.9 \sim 95.1$ & $99.9 \sim 95.5$ & $99.9 \sim 95.5$ & $99.9 \sim 95.2$ & $97.6 \sim 94.4$ \\
\hline $\begin{array}{l}\text { Asian } \\
\text { isolates }\end{array}$ & $99.9 \sim 89.4$ & $99.9 \sim 89.4$ & $99.9 \sim 89.5$ & $99.9 \sim 89.5$ & $99.9 \sim 89.4$ & $99.9 \sim 89.5$ & $99.9 \sim 89.5$ & $99.9 \sim 89.5$ & $99.9 \sim 87.5$ \\
\hline $\begin{array}{l}\text { Europe } \\
\text { isolates }\end{array}$ & $93.2 \sim 92.4$ & $93.2 \sim 92.4$ & $93.9 \sim 93.2$ & $93.9 \sim 93.2$ & $93.7 \sim 93.5$ & $93.9 \sim 93.2$ & $93.9 \sim 93.2$ & $93.7 \sim 93.5$ & $92.9 \sim 92.7$ \\
\hline $\begin{array}{l}\text { African } \\
\text { isolates }\end{array}$ & $8.5 \sim 8.4$ & $8.5 \sim 8.4$ & $8.7 \sim 8.5$ & $8.4 \sim 8.2$ & $8.9 \sim 8.8$ & $8.7 \sim 8.5$ & $8.4 \sim 8.2$ & $8.5 \sim 8.4$ & $8.9 \sim 8.8$ \\
\hline $\begin{array}{l}\text { USA } \\
\text { isolates }\end{array}$ & $93.0 \sim 10.7$ & $93.0 \sim 10.7$ & $93.8 \sim 9.9$ & $93.8 \sim 9.9$ & $93.3 \sim 10.6$ & $93.8 \sim 9.9$ & $93.8 \sim 9.9$ & $93.3 \sim 10.5$ & $93.3 \sim 10.5$ \\
\hline $\begin{array}{l}\text { Iraq } \\
\text { isolates }\end{array}$ & $89.8 \sim 10.3$ & $89.8 \sim 10.3$ & $89.8 \sim 10.3$ & $89.8 \sim 10.3$ & $92.7 \sim 10.3$ & $89.8 \sim 10.3$ & $89.8 \sim 10.3$ & $91.9 \sim 10.3$ & $91.1 \sim 10.3$ \\
\hline $\begin{array}{l}\text { Japan } \\
\text { isolates }\end{array}$ & $94.5 \sim 14.0$ & $94.5 \sim 14.0$ & $94.5 \sim 14.7$ & $94.5 \sim 14.7$ & $94.3 \sim 13.5$ & $94.5 \sim 14.7$ & $94.5 \sim 14.7$ & $94.4 \sim 14.1$ & $93.5 \sim 13.4$ \\
\hline $\begin{array}{l}\text { Goat } \\
\text { originated } \\
\text { isolates }\end{array}$ & $99.9 \sim 94.7$ & $99.9 \sim 94.7$ & $99.9 \sim 95.5$ & $99.9 \sim 95.5$ & $99.9 \sim 95.1$ & $99.9 \sim 95.5$ & $99.9 \sim 95.5$ & $99.9 \sim 95.2$ & $99.9 \sim 94.4$ \\
\hline $\begin{array}{l}\text { Sheep } \\
\text { originated } \\
\text { isolates }\end{array}$ & $96.2 \sim 7.7$ & $96.2 \sim 7.7$ & $97.0 \sim 9.7$ & $97.0 \sim 9.7$ & $96.7 \sim 9.7$ & $97.0 \sim 9.7$ & $97.0 \sim 9.7$ & $96.8 \sim 9.9$ & $96.0 \sim 9.8$ \\
\hline $\begin{array}{l}\text { Camel } \\
\text { originated } \\
\text { isolates }\end{array}$ & $89.7 \sim 89.4$ & $89.7 \sim 89.4$ & $90.6 \sim 90.2$ & $90.6 \sim 90.2$ & $89.7 \sim 89.4$ & $90.6 \sim 90.2$ & $90.6 \sim 90.2$ & $90.2 \sim 89.5$ & $88.1 \sim 87.9$ \\
\hline $\begin{array}{l}\text { Oreamnos } \\
\text { americanus } \\
\text { isolate }\end{array}$ & $93.0 \sim 7.3$ & $93.0 \sim 7.3$ & $93.8 \sim 7.3$ & $93.8 \sim 7.3$ & $93.3 \sim 7.7$ & $93.8 \sim 7.3$ & $93.8 \sim 7.3$ & $93.3 \sim 7.6$ & $93.3 \sim 7.6$ \\
\hline BPSV & $38.3 \sim 37.6$ & $38.3 \sim 37.6$ & $39.1 \sim 38.3$ & $39.1 \sim 38.3$ & $38.7 \sim 37.9$ & $39.1 \sim 38.3$ & $39.1 \sim 38.3$ & $39.2 \sim 38.4$ & $39.2 \sim 38.4$ \\
\hline PCPV & $89.4 \sim 88.6$ & $89.4 \sim 88.6$ & $90.2 \sim 89.4$ & $90.2 \sim 89.4$ & $89.4 \sim 88.6$ & $90.2 \sim 89.4$ & $90.2 \sim 89.4$ & $89.5 \sim 88.7$ & $87.1 \sim 87.1$ \\
\hline
\end{tabular}

Figure 2

\section{PCR results of study isolates against ORFV}

DNA Ladder (50-500 bp): Lane 1

ORFV positive samples: Lane B, C, D, E, G, N (408 bp)

ORFV negative samples: Lane F, H, I, J, K, L, M 


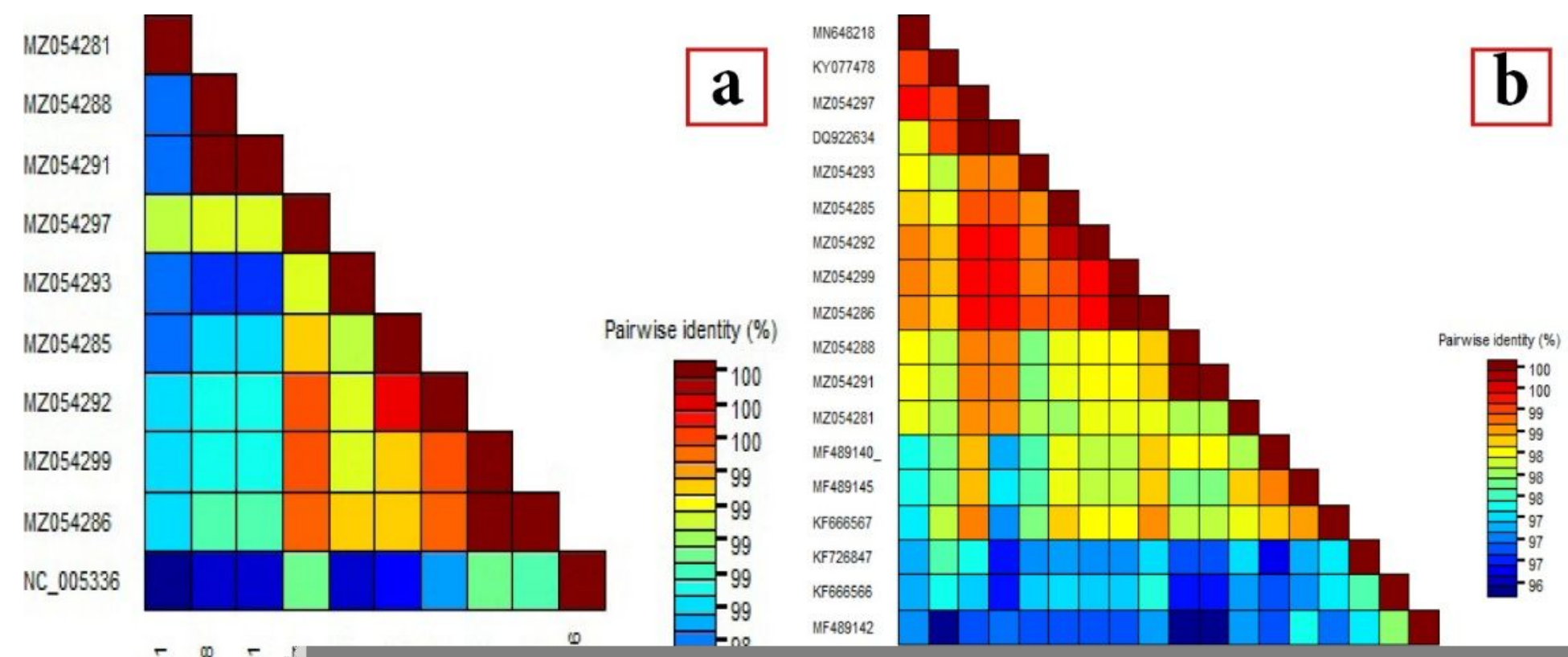

Figure 3

The percentage nucleotide homology between; (a). study isolates and reference strain of ORFV (NC_005336); (b). study, Indian and Chinese isolates of ORFV 


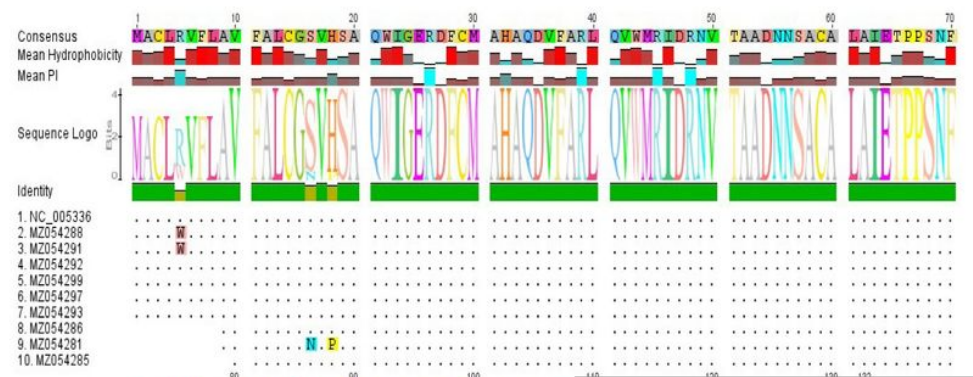

\section{Figure 4}

The amino acid substitutions between; (a). study isolates and reference strain of ORFV (NC_005336); (b). study, Indian and Chinese isolates of ORFV 


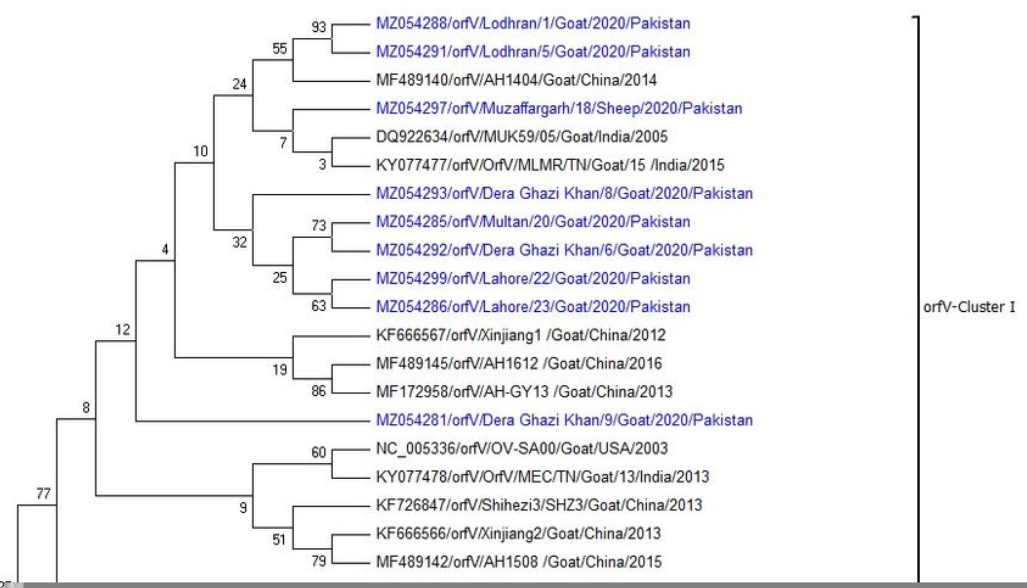

Figure 5

The phylogenetic analysis of studied and previously reported parapoxviruses 


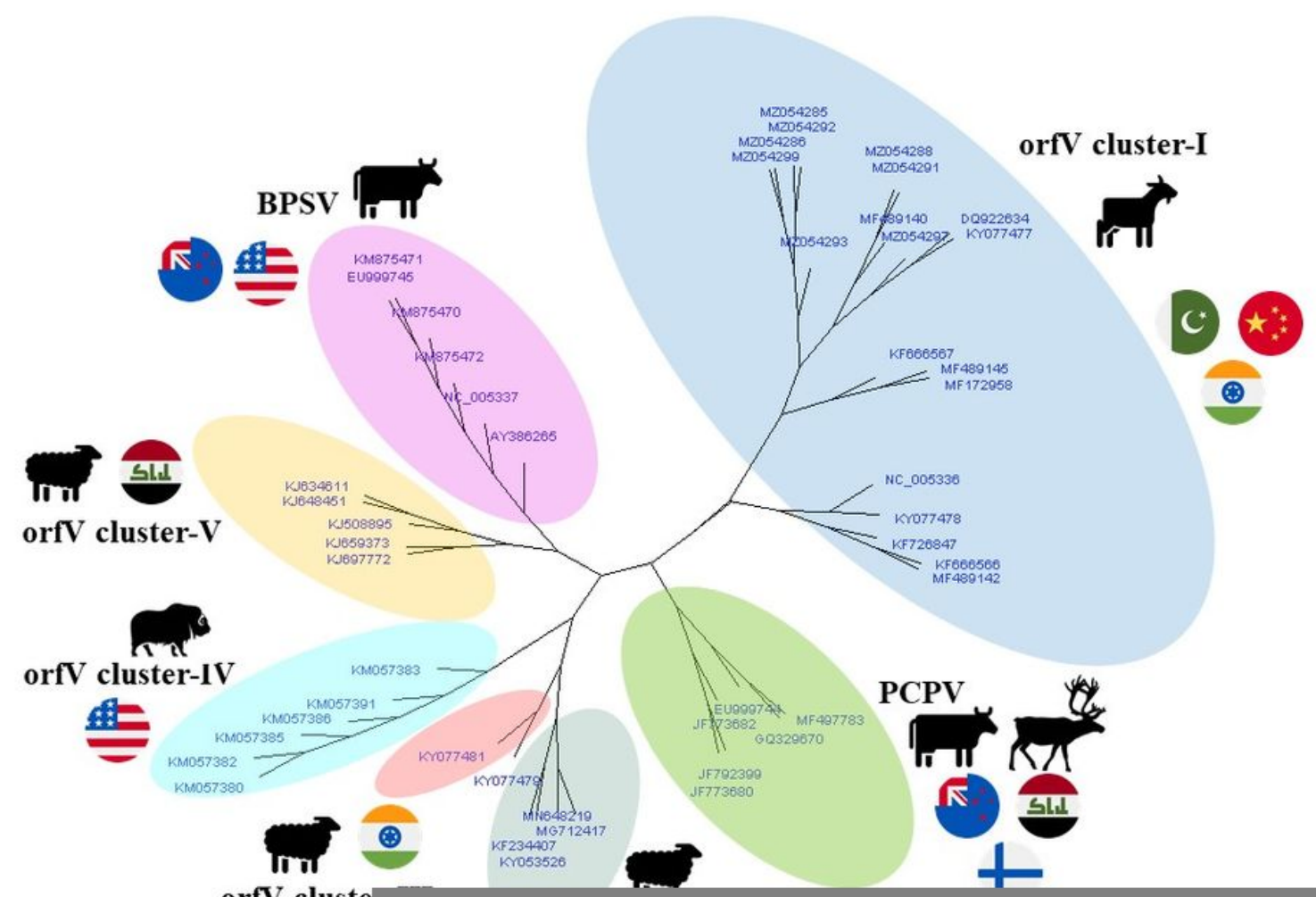

Figure 6

The GIF/IL-2 gene based evolutionary network of study-included isolates representing Clade-wise distribution of parapoxviruses 

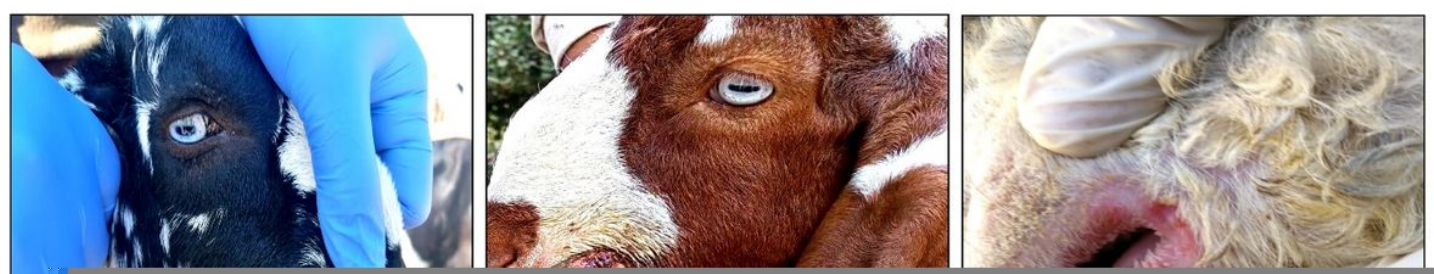

\section{Figure 7}

\section{Gross lesions of ORFV infected sheep and goat}

$(a, b)$. severe proliferative orf lesions on upper and lower lips of goats; (c). erythema on upper and lower lips of sheep; (d). papule and pustules on upper and lower lips of goat; (e). papule and pustules on teat of goat; (f). thicker, brownish, quickly accretive scabs on muzzles of goat; (g). thicker, greyish, rapidly accretive scabs on upper and lower lips of goat; $(\mathrm{h})$. advanced lesions in the form of thicker, black to brown, scabs on upper and lower lips, mouth commissure and nostrils of sheep; (i). healing and regeneration on lips of sheep. 

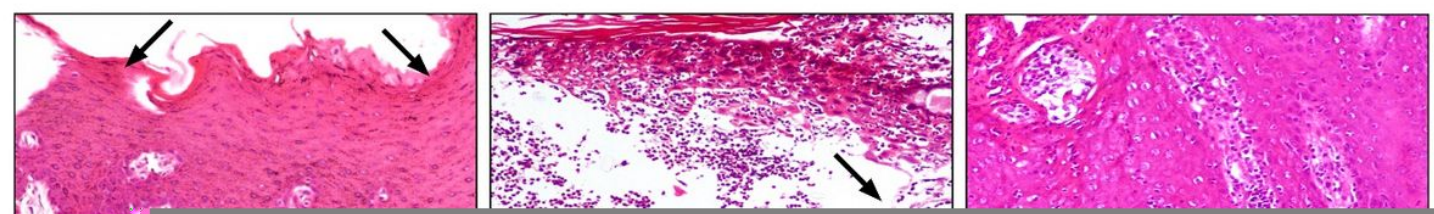

\section{Figure 8}

\section{Microphotographs of skin of ORFV infected animals (H \& E stain).}

(a). Epidermal hyperplasia with hyperkeratosis and parakeratosis (black arrow, 10X); (b). epithelium ulceration and replacement by necrotizing crust (black arrow, 10X); (c). epidermis extends into dermis to form anastomosing rete ridges (black arrow) and spongiosis in spinous cells of stratum spinosum (blue arrow, 10X); (d). vacuolation (black arrow) and necrotic area in the epidermis (blue arrow, 10X); (e). micro-abscess (black arrow) and scab formation (yellow arrow, 10X) in the epidermis; (f). Inflammatory cells infiltration in the dermis (black arrow, 10X); (g).

eosinophilic intracytoplasmic inclusion bodies within keratinocytes (black arrow) and intraepidermal edema (blue arrow, 40X); (h). peripheralized keratohyalin granules in the epidermis (black arrow, 40X); (i). scattered interstitial hemorrhages in the dermis (black arrow, 40X). 